\title{
VAMPIRE BAT CONTROL IN MEXICO ')
}

\author{
by
}

U. SCHMIDT 2), A. M. GREENHALL ${ }^{3,4}$ ) \& W. LOPEZ-FORMENT ${ }^{3}$ )

\section{INTRODUCTION}

Though usually beneficial, bats sometimes are a nuisance to humans (Greenhall \& Stell, 1960), or may even constitute serious economic problems and health hazards. Most important in this respect are the vampire bats, especially of the genus Desmodus, which are abundant from northern Argentina through the whole of Latin America to the north of Mexico. The agricultural problem is caused on the one hand by weakening of the cattle through loss of blood, making them more susceptible to diseases and parasite infestation, as well as by transmitting paralytic rabies (Derriengue).

An organized control of vampires has only been established in Trinidad (Greenhall, 1958). On the American continent some control efforts were undertaken sporadically by local veterinarians and cattle owners. They comprise mainly dynamiting or fumigating caves or burning hollow trees. As the controllers usually cannot distinguish between a vampire bat and another bat, they destroy more benefical bats than vampires and do more harm than good.

Since 1968, the Paralytic Rabies Research Project of the Food and Agriculture Organization of the United Nations, in cooperation with the Mexican government, has been investigating the bovine paralytic rabies problem in Mexico, which involves vampire control.

Up to now, no specific control methods for vampires are known. Much more basic research on the ecology and physiology of the vampire bat is need-

1) F.A.O. Paraytic Rabies Research Project, Contribution No. 23.

2) Zoophysiologisches Institut, 74 Tübingen, B.R. Deutschland.

3) UNDP/FAO Paralytic Rabies Research Project, Ap. Post. M-10778, Mexico 1, D.F, Mexico.

4) Smithsonian Institution, Washington D.C., U.S.A. ed to find a biological or chemical method for reducing the vampires without harming other bat species. Therefore the conventional control methods, as described by Greenhall (1963), were applied in control studies. These methods involve protection of heavily bitten cattle with nylon mistnets, shooting and netting at vampire roosts or catching the bats in front of the roosts with the Constantine trap (Constantine \& Villa, 1962). In some cases, strychnine-syrup may be applied on fresh bites; the vampires are poisoned, when they to the wound.

\section{STUDY AREAS AND METHODS}

The control studies were done at two different locations. One was the Government ranch Las Margaritas (LM), in the north-east of the state of Puebla; the other one was a small private ranch near Estacion Vicente (EV), in the eastern part of the state of Oaxaca. The situation was completely different in both places. Rancho Las Margaritas is situated at the slope of the Sierra Madre Oriental, at about $500 \mathrm{~m}$ altitude. The region is mountainous with many small valleys and rivers, partly covered with tropical rain forest, pastures, coffee and banana plantations or corn fields. Many cattle graze everywhere. No Derriengue has been reported in this area. We were called to Estacion Vicente during a heavy Derriengue outbreak. This region is mainly sugar cane country. The ranch is located at the base of the Sierra Madre Mazateca, which is covered with tropical forest. 40 to 50 milk cattle were in a very restricted area; no other cattle were found within 5 to $10 \mathrm{~km}$ on each side. Presumably most of the vampires of this area are feeding on this herd. This explains, why these animals were extremely heavily bitten. Hollow trees and caves were found in both locations. In LM the control was carried out by catching or shooting the vampires in their roosts. Two tree- 
roost and 10 cave roosts were found in a radius of about $6 \mathrm{~km}$ around the ranch. As many vampires as possible were removed in 6 to 8 weekly intervals from May to October 1969. In EV, the vampires were caught by netting them around cattle with mistnets in February, May, July and September.

\section{AMOUNT OF BITING OF CATTLE}

To establish the efficiency of control operations, the vampire bites on cattle were counted before and after the control. Investigation of the stomach and gut contents of 98 vampires from LM by the precipitin technique had shown that more than $80 \%$ were feeding on cattle, the remaining ones on horses, pigs and chickens. As the majority of vampires were feeding on cattle, efficient control should result in a marked decrease of the biting index.

In LM, a sample of more than 500 heads of cattle was inspected in April and November. As the counting had to be made on horseback in the pastures, it was impossible to distinguish between fresh bites and older ones. In EV the cattle were brought to a corral every morning and therefore it was possible to consider only bites from the preceeding night.

In LM the amount of biting decreased from 529 bites on 566 heads of cattle in April to 100 bites on the same number of animals. In the meantime, 516 vampires were removed. The 42 cows in EV had a total of 98 bites in May. After removing 64 vampires, the biting dropped to 76 in July. Later, 55 bats were caught; the next count, the 9 September, revealed 45 bites. The next morning, 29 fresh bites were seen. During the night it was raining quite heavily. Vampires are reluctant to fly in the rain (Wimsatt, 1969), which may account for the low biting index. During the night from 10 to 11 September, all the cattle were restricted in a corral, surrounded by nets, and 63 vampires were caught. After the catch, the 12 September, 16 bites were counted, and the next day, 22 fresh bites. One month later, without any further catching, 24 bites were found.

At both locations the cattle populations were of different breeds. In LM there were Cebu, Swiss, Santa Gertrudis and Charolais; later they introduced a few Hereford cattle. In EV mainly Cebu and Holstein, some mixed breeds (Holstein/Cebu, Holstein/Swiss) and a few Swiss cattle were kept.

There were great differences in the amount of bitting between the different breeds. In LM the Swiss cattle were bitten most frequently (table I),
Table I.

Distribution of biting in different breeds of cattle in Las Margaritas

\begin{tabular}{lrcrrrrr} 
& & \multicolumn{3}{c}{$\begin{array}{c}\text { April } \\
\text { bites/ }\end{array}$} & & \multicolumn{3}{c}{$\begin{array}{c}\text { November } \\
\text { number }\end{array}$} & \multicolumn{2}{c}{ bites/ } \\
& number & numim. & of bites \\
& anim. & of bites & anim. & of bites \\
Cebu & 91 & 0.208 & 19 & 108 & 0.009 & 1 \\
Swiss & 127 & 1.984 & 252 & 131 & 0.412 & 54 \\
S. Gertrudis & 127 & 0.700 & 89 & 118 & 0.186 & 22 \\
Charolais & 221 & 0.764 & 169 & 194 & 0.103 & 20 \\
Hereford & - & - & - & 15 & 0.200 & 3
\end{tabular}

Cebu were bitten least, $\mathrm{S}$. Gertrudis and Charolais were intermediate. In EV, Holstein cattle were most heavily attacked, Cebu again were least preferred, mixed breeds were quite heavily bitten too.

These differences were always found, where mixed cattle populations were present. It is not known what factor determines the selective feeding behavior. It may be different cattle behavior, as Cebu are more agile and react more strongly against the vampire attack than Holstein or Swiss cattle; or there may be a physiological factor involved, some skin or blood substance attracting or repelling the vampires. In areas with a pure Cebu population (Yucatan or San Luis Potosi), these Cebu are as heavily bitten as Swiss and Holstein elsewhere.

\section{ESTIMATION OF POPULATION DENSITIES}

The experiments in EV give the opportunity to get some clues on the number of vampires that feed on one wound. This seems important in establishing vampire bat population density indices by counting the bites on cattle, as well as for estimating blood losses.

EV was a particularly suitable place for this kind of study, as presumably most of the vampires were feeding on this herd. As described above, during the night from 10 to 11 September, 63 vampires were caught. In the mornings before catching operations, 45 and 29 bites were counted, subsequently 16 and 22 bites. Bringing the number of bats removed into relation with the decrease of biting, it seems, that several vampires are feeding from one wound, at an average of 2.5 to 3.5 vampires per bite. Observing the attack of vampires in this ranch with night vision scopes, we had seen 7 vampires feeding from the same wound, one after the other, during a three hour period of time. Estimating a vampire population even in a favor- 
able place is very difficult. After the control, 20 to 25 bites were counted. If at an average 3 vampires are feeding on one wound, and approx. $80 \%$ are feeding on cattle, one can estimate a remaining population of about 80 to 100 bats. In May about 100 bites were counted and in the meantime 182 vampires were removed. This amounts to about 280 to 300 vampires before the control. These assumptions were made, disregarding movements of the population, which may alter the figures, and disregarding the possibility that vampires are not feeding every night.

\section{FORAGING ACTIVITY}

Wimsatt (1969) found that the bulk of the foraging activity was restricted to the early evening hours. In EV we attended the nets on two nights, in February and September, from evening to morning (table II). About $70 \%$ of the bats were

Table II.

Number of vampires caught during two nights, in hourly intervals.

21:00 22:00 23:00 24:00 1:00 2:00 3:00 4:00 5:00

$\begin{array}{llllllllll}\text { Sep. } & 7 & 17 & 10 & 7 & 5 & 6 & 4 & 3 & 1\end{array}$

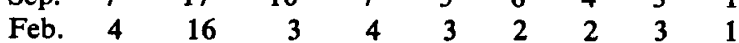

caught before midnight, with a sharp peak between 9 and 10 o'clock. The remaining $30 \%$ were caught between midnight and 5 o'clock in the morning. During both nights, the weather conditions were very favorable, without rain or moon.

For netting around cattle as a control method, these findings suggest, that catching could be done most effectively from sunset to midnight.

\section{CONCLUSIONS}

The control studies in EV and LM have shown that considerable relief from vampire predation can be achieved simply by removal of vampires through conventional methods, either from roosts or by catching them around the cattle. In both study areas the biting decreased by 70 to $80 \%$ after half a year of control operations.

To make the control economically feasible, the concerned Government authorities should establish small, well trained control teams, to service the cattle associations. The service should include active control, but should mainly aim at the training of local groups, teaching them to distinguish vampires from other bats, to find their roosts and to use mistnets, handnets, firearms etc. for effective and selective destruction of vampires. These local groups should undertake catching operations in 2monthly intervals. In this way, a control program could be established, until more specific, more effective, and more economic methods of vampire control will be developed.

\section{LITERATURE}

Constantine, D. G. \& B. Villa R., 1962. Metodos de lucha contra los vampiros transmisores de la rabia. Bol. ofic. Sanit. Panamericana, 53 : 7-12.

Greenhall, A. M., 1963. Use of mistnets and strychnine for vampire control in Trinidad. J. Mamm., 44 : 396-399.

- , 1968. Bats, rabies and control problems. Oryx, 9 : $263-266$.
Greenhall, A. M. \& G. Stell, 1960. Binomics and chemical control of free-tailed house bats (Molossus) in Trinidad. Fish Wildlife Serv., spec. sci. Rep. Wildlife, 53 : $1-20$.

WimsatT, W. A., 1969. Transient behavior, nocturnal activity patterns, and feeding efficiency of vampire bats (Desmodus rotundus) under natural conditions. J. Mamm., 50 : 233-244. 